\title{
Policy on manager involvement in work re-integration: Managers' experiences in a Canadian setting
}

\author{
Karin Maiwald ${ }^{\mathrm{a}, *}$, Agnes Meershoek ${ }^{\mathrm{b}}$, Angelique de Rijk ${ }^{\mathrm{a}}$ and Frans J.N. Nijhuis ${ }^{\mathrm{c}}$ \\ ${ }^{a}$ Care And Public Health Research Institute (CAPHRI), Department of Social Medicine, Faculty of Health, \\ Medicine and Life Sciences, Maastricht University, Maastricht, the Netherlands \\ ${ }^{\mathrm{b}}$ CAPHRI, Department of Health Ethics and Society, Faculty of Health, Medicine and Life Sciences, Maastricht \\ University, Maastricht, the Netherlands \\ ${ }^{\mathrm{c}}$ CAPHRI, Department of Work and Organizational Psychology, Faculty of Health, Medicine and Life Sciences, \\ Maastricht University, the Netherlands
}

Received 11 December 2012

Accepted 22 April 2013

\begin{abstract}
.
BACKGOUND: In Canada and other countries, sickness absence among workers is a significant concern. Local return-to-work policies developed by both management and workers' representatives are preferred to tackle the problem.

OBJECTIVE: This article examines how managers perceive this local bipartite agreed upon return-to-work policy, wherein a social constructivist view on the policy process is taken.

METHODS: In-depth interviews were held with 10 managers on their experiences with execution of this policy in a Canadian healthcare organization. Interviews were transcribed verbatim and qualitative analyses were completed to gain deep insight into the managers' perspectives.

RESULTS: Results show that the managers viewed themselves as a linchpin between the workplace and the worker. They did not feel heard by the other stakeholders, wrestled with worker's limitations, struggled getting plans adjusted and became overextended to meet return-to-work objectives.

CONCLUSIONS: The study shows that the managers felt unable to meet the responsibilities the policy demanded and got less involved in the return-to-work process than this policy intended. RTW policy needs to balance on the one hand, flexibility to safeguard active involvement of managers and, on the other hand, strictness regarding taking responsibility by stakeholders, particularly the health care and re-integration professionals.
\end{abstract}

Keywords: Discretionary space, managers' perspectives, return-to-work, sickness absence, social constructivist policy analysis

\section{Introduction}

In Canada, as well as in other societies, sickness absence is a significant concern and challenge [1-3]. In

${ }^{*}$ Corresponding author: Karin Maiwald, Department of Social Medicine, Faculty of Health, Medicine and Life Sciences, Maastricht University, Maastricht, the Netherlands. P.O. Box 616, 6200 MD, Maastricht, the Netherlands. Tel.: +31 43 3882223; Fax: +31 43 3884169; E-mail: k.maiwald@maastrichtuniversity.nl. particular the health care workforce faces the risk of illness [4]. Therefore policymakers from various countries have agreed to find solutions [5].

Several policies and interventions for return to work (RTW) have been tried in Canada. They are often referred to as disability management (DM), that is "a process in the workplace designed to facilitate the employment of persons with a disability through a coordinated effort and taking into account individual needs, work environment, enterprise needs and legal responsi- 
bilities" [5, p. 3]. Westmorland and Buys identified key DM principles from the literature namely: integrated prevention and remediation; corporate leadership; joint union and management collaboration; timely return to work and employee involvement [6]. New policies were developed to support early RTW of workers with incapacities (the inability to work due to sickness or injury). These particular strategies do, however, not always have the expected results from the perspectives of re-integrating workers with incapacities in Canada [611]. Workers' disappointment with early RTW policy is also found in other countries [12].

To improve effectiveness of RTW, collaboration was sought with both management and worker organization representatives when developing RTW policy in Canada: the so called bipartite policy-making approach. At the provincial level, this bipartite policy process has even been institutionalized $[13,14]$. In this setting, provincial Occupational Health and Safety (OHS) regulations and legislation define DM intervention programming per industrial sector. Taking the bipartite perspectives into account is firmly believed to an effective remedy to reduce sickness absence [15] due to reduction of bottlenecks in the planning, implementation and management of RTW programming [16, 17]. Involvement of bipartite stakeholders to formulate the RTW policy in British Columbia (BC), Canada for the healthcare sector seemed, however, not to prevent practical bottlenecks when implementing the policy according to the diverse stakeholders [10]. These findings raise the question what the reasons are for stakeholders' difficulties in the execution of RTW policy and that is the focus of our research.

In 2009, RTW policy in BC, Canada for the healthcare sector was reformed as part of the collective bargaining process between the provincial government and healthcare management- and trade union representatives. Local bipartite stakeholders (human resource executive and management, senior executive, trade union representatives) also provided input in policymaking process. This new bipartite agreed upon RTW policy was built upon earlier provincial, sector-specific initiatives [18].

The finding of our earlier study on the workers' perspectives on the reformed RTW policy in practice showed that the policies and procedures made workers with incapacities responsible for the design of RTW plans. At the same time, however, re-integrating workers considered themselves incapable to answer this responsibility, within which they were offered too little flexibility regarding involvement and interventions in RTW planning to meet their needs [11].
Our current study focuses on the managers' perspectives on RTW policy in practice. The scarce literature that takes a manager perspective on RTW policies and procedures illustrate this particular stakeholder group struggles with not knowing how to respond to the worker with health problems [19], finds it difficult that re-integrating workers may not be qualified to meet certain functions in terms of limitations and productivity demands [20], and worries about increased costs and fear legal liability [21]. The scarce studies also show that RTW decisions and outcomes are affected by managers' behaviour [22,23].

To study how RTW policy works from the managers' perspectives in the BC healthcare practice, a social constructivist view on the policy process [24] is taken. Policy often turns out differently and in unexpected ways in practice and can have normative implications [24]. This happens because policies and procedures that have to govern daily practice include general rules that are based on general assumptions of the situations in that same practice. Therewith rules and policies permit discretionary space for those stakeholders who deliver the services and have to apply rules and policies on individual situations [24,25].

Discretionary space, on the one hand, allows for including individual differences and contextual circumstances in decision-making in the execution of rules and policies in practice. Thus discretionary space is thought to enhance fairness in process. On the other hand, as the rules and policies itself do not predict how the discretionary space is used in practice, this space also counts for transformations in rules and policy intentions in practice. In applying abstract rules and policies to concrete individual cases, rules have to be interpreted. This process of interpretation-in practice is influenced by professional norms, social costumes, peer norms, moral beliefs and existing practices which may transform the meaning of the rules and policy-as intended [24-29]. Research of Meershoek et al. [26,27], for instance, showed how administrative procedures can have counter-productive effects in practice in the Dutch setting of work re-integration. They concluded that, in practice, the duty for the employers to work on re-integration of workers who reported ill became an empty letter, due to formal procedures and control mechanisms.

The application of rules and policies is thus a highly contextual enterprise, and therefore implementation process in practice often has consequences that cannot be predicted by the policy itself [24]. Insight in and understanding of the environmental and workplace 
context in which the rules and policy have to function can help to formulate rules and policy that are better adapted to this local context, within which the risk of unintended consequences can be reduced.

In our research into Canadian RTW rules and policy execution, we therefore investigate how RTW policy functions in practice in the $\mathrm{BC}$ healthcare sector. How do local stakeholders interpret and apply the new RTW policy, which is intended to add to what is already arranged by social security legislation in Canada and how do these stakeholders handle the discretionary space? Insight in these practices will answer the question whether bipartite stakeholder involvement in the RTW policy development phase in policy process indeed guarantees that policies and procedures are adjusted to the dynamics of daily re-integration practice. In this article we focus on the perspective of the managers of workers who had reported ill and were reintegrating in their own or in accommodated jobs.

\subsection{The policy studied}

The RTW policy in this setting contains the following aspects. Generally, both the managers and individual workers are expected to participate in coordinating the organization of early RTW activities and development, wherein absent workers should reintegrate before full recovery of either their incapacities has taken place. Organizational structures to positively affect RTW include a workplace-based disability management professional (DMP) (so called: case manager) who is supposed to contact the worker to request their participation in RTW programming and ask for the workers input in RTW planning (e.g., either a straightforward plan for less than six weeks in duration or a complex plan for longer than six weeks). The DMP is further supposed to check with, follow-up and contact the manager and other stakeholders (e.g., the physician, a trade union steward and insurer/compensation agent) to aide and steer decision-making during reintegration. RTW programming is supposed to include access to various support services (e.g., ergonomist, workplace rehabilitation advisors). A supernumerary ('extra') worker can be made available upon RTW as well as access to internal human resources (e.g., help with the implementation of work -, job accommodations and further care). Participation in RTW programming is voluntary in the first six weeks of sickness absence but mandatory thereafter and must include the consent of the worker's physician. External health and safety programming services may also help with the implementation of work-, job accommodations and further care (as described below).

\subsection{Social security in Canada}

As said, in Canada, as in many other countries, RTW policy only adds to what is already arranged by social security legislation. In the BC healthcare sector, management is responsible for disability benefits for workers who experience work-related injury/illness under the Workers Compensation Act and OHS regulations. If sickness absence is deemed not work-related or is result of a motor-vehicle accident that is non-work related, there are various other insurance and benefits systems available. For all workers, basic health care costs are covered on the basis of a public healthcare system.

Employment status for regular staff is secured for about two years during which management needs to relate to the Compensation Act and OHS regulations. Benefits and coverage for workers vary per cause of sickness absence and collective agreement. The management has an obligation to make every reasonable effort to find a way to accommodate the worker (e.g. must carefully scrutinize their workplace for potential jobs into which the worker can be placed or, if equipment is required, investigate the cost of purchasing such equipment).

\subsection{Aim and research questions}

The aim of this article is to gain deep insight in managers' perspectives on reformed bipartite-agreed RTW policies and procedures in practice. The experiences with and perceptions on the reformed bipartiteagreed RTW policy is part of our study how RTW policy works in practice to, in turn, find out how bipartite involvement in policy process in the $\mathrm{BC}$ healthcare sector functions. The research questions are:

1) How do the managers experience their new role in organizing RTW trajectories for absent workers described in the bipartite-agreed upon RTW policy?

2) To what extent is the bipartite agreed upon RTW policy to give local managers more responsibility perceived as successful by the managers?

3) How are contributions by the DMPs to steer and guide collaboration in the relation managementworker in RTW experienced and perceived by the managers?

\section{Methods}

This study took place in the largest and considered leading health organization in $\mathrm{BC}$, Canada which pro- 
Table 1

Detailed summary of participant characteristics

\begin{tabular}{|c|c|c|}
\hline \multicolumn{3}{|c|}{ Clinical managers and supervisors (10 interviewees) } \\
\hline $\begin{array}{l}\text { Participants supervise(d) workers with cause } \\
\text { of sickness absence of } \\
\text { (as diagnosed by physician) }\end{array}$ & $\begin{array}{l}\text { Medical disorder } \\
\text { Orthopaedic* }\end{array}$ & $\begin{array}{l}\text { Work-related } \\
\text { Not-work related } \\
\text { Motor vehicle accidents }\end{array}$ \\
\hline \multicolumn{3}{|c|}{ Systemic } \\
\hline & \multicolumn{2}{|l|}{ Mental disorder } \\
\hline Positions & \multicolumn{2}{|c|}{$\begin{array}{l}\text { Regional Supervisor; Team Director; Team Leader; Clinical Supervisor; Regional Practice } \\
\text { Lead; Charge Nurse; Supervisor }\end{array}$} \\
\hline Age & \multicolumn{2}{|l|}{$35-60$ years of age } \\
\hline Gender & 8 Female & 2 Male \\
\hline Health care services & \multicolumn{2}{|c|}{ Hospital; Community Health Centre; Clinic; Residential Care } \\
\hline
\end{tabular}

vides general and specialized public healthcare services to a large portion of the provincial population. Public acute health care services are offered in their 13 hospitals across a vast geographical area whereby they also offer a number of other services including, primary care, community-based residential and home health care, mental health, addiction services and public health. As per provincial collective agreements, this organization created workplace-based RTW policy for its 22,000 workers. To find answers to our research questions, qualitative research methods were selected [30-32] and to obtain good insight on the experiences and perceptions of the management, in-depth individual interviewing was selected as the best method of data gathering [31]. The first author performed the data collection and had the main role in data analysis. All authors had experience with qualitative data collection and analysis. Besides the involvement of the other authors, two staff members of the Occupational Health and Safety Agency for Healthcare (OHSAH) of BC supervised the data-collection. OHSAH had been involved in the development and evaluation of the workplace-based RTW policy. The first author and supervisors did have professional work relationships with the participating $\mathrm{BC}$ health care organization. None of the authors or supervisors had professional or private relationships with the interviewees.

\subsection{Study sample}

Managers were defined as the clinical managers and direct supervisors. Inclusion criteria were that they had or still were involved in re-integration of staff with work incapacities anytime between April 2009, when the 'new' RTW policy came into effect, and June 2010. Managers who only had experiences with reintegrating workers previous to April 2009 were ex- cluded from this study. Purposive sampling with various recruitment strategies were used to maximize variability in perspectives and to acknowledge the opportunity to obtain information from the full range of local managers for intensive study [30,33]. The first round of interviews with eight managers was held between September and December 2009 and the second round with two managers was held in May 2010. When a manager initiated contact to participate, he/she received a detailed four-page information sheet and upon agreement to participate an interview was booked. Interviewees ranged in management-level, differed in age from 35-60, included both new and experienced managers, and managed various size department, delivered differing health care services at multiple work sites (see Table 1 for a description of participant characteristics).

\subsection{Ethical considerations}

For this study, support was obtained from the organization itself and various trade unions (three - all of which had been part of the policy process) to conduct this study. Further, we received the approval of two local Research Ethics Boards from the University of BC and the health organization. Interviewees were made aware they were free to refuse to participate and were welcomed to ask questions and express concerns about the study any time. Informed consent forms to participate, record the interview, and review the findings were signed prior to each interview. Participants were given the option to receive the final report.

\subsection{Interview procedure}

The topic list was based on administrative materials about the local RTW policy formal documents and 
draft papers (e.g. brochures, procedures on DM that were collected via DMPs and the organization's intranet), RTW literature and from policy science. The topic list included the following topics: on imposing rules and responsibilities, monitoring and reviewing, decision making, controversy and conflict, influence and authority structures in RTW. To increase validity, interviewees were invited to address these topics by means of various real worker cases they brought up themselves during the interviews. They were also given the opportunity to elaborate on topics they brought up on RTW in this setting. Interview questions were finetuned as data collection progressed. The individual face-to-face interviews were conducted in managers' office, took from $40 \mathrm{~min}$ to two h, and were taped and transcribed verbatim.

\subsection{Analysis}

Following ethnographic methodologies, qualitative analyses were completed to gain deep insight into stakeholders' perspectives [34,35], within which detailed understanding of interviewees' experiences, actions and practical reasoning was gained [31,32]. By identifying, coding and categorizing experiences and perceptions [36] (with pen and paper and word processor) and, then, pattern-seeking to interpret experienced challenges and opportunities [30] we were able to unravel how practical bottlenecks affected RTW. Our interpretative analyses [31,32,34] focused on the role of policy, legislation, organization characteristics and the individual context on involvement; and how that affected RTW activities, from managers' perspectives. The analysis of RTW policy as experienced and perceived by these stakeholders resulted in an empirical description of organizational process in RTW and the typical consequences in practice. A review process was put in place to ensure the accuracy of the descriptions, emerging themes, and revealed arguments between the authors. After the first round of interviews, the first and second author performed the first-phase of the dataanalysis (structuring data, initial coding). After the second round of interviews, the interpretations and patterns were discussed stepwise during the process of analysis among all authors. Member checking, to review preliminary study findings for the purpose of accuracy by interviewees, was not done in this study.

\section{Results}

On the basis of the experiences and perceptions of the managers, we identified three main phases re- garding their involvement in RTW: (1) return-to-work plan design; (2) execution of the return-to-work plan; and (3) final re-integration strategy. In practice, reintegration is not clearly structured; the RTW process is not simply onward and upward and is everdeveloping. We describe the most central experienceaspects or bottlenecks that succinctly dominate in these phases. However, the experiences do not limit itself to the phase in which we describe it.

\subsection{Developing a return-to-work plan: Feeling unheard}

The procedure calls for a DMP to determine safe work options for the re-integrating worker. A group meeting is supposed to be held with the manager, worker, union steward, and possible other stakeholders to review and finalize details of the plan. The managers argued that involvement is difficult and they identified concerns in practice. RTW plans need medical accordance and approval by the insurance/compensation agency.

The managers' first concern was that RTW policies and procedures were unclear to them. In some situations the managers felt unaware of where to find this information.

'How does it work? Who is responsible for what? That would be nice to have, an outline, kind of how this process works and for the employee to be able to say: Okay, at this point I should be here, and this is who I would contact if I had any concerns.'

Besides difficulties experienced in finding information on policies and procedures, the second concern the managers indicated was that an expected routine in organizing re-integration was not happening. According to the managers, not getting regular updates around workers' progress, an anticipated re-integration date and readiness for work was confusing.

'It was all very confusing (...) you know, getting information and making sure the person's ready.'

Besides challenges perceived in getting information on worker's progress and confusion around organizing re-integration, the third concern the managers pointed out were the developments of the RTW plans itself. As explained above, the managers were interested in finding out whether the worker was ready for work. This was mostly because their experience told them that over- or underestimations of work abilities by workers themselves, including pressure and coercion by in- 
surers and trade union stewards do take place. Keeping the right to privacy in mind, the managers stated it was nevertheless difficult that the assessment on work abilities was kept silent, that ways on how the assessments on limitations and hours came about was not made clear and that they were given no guidelines or direction on what they could or could not say to make suggestions to adjust the plan (e.g. during contact moments).

'I wanted to make it work and I didn't want to have unnecessary conflict (...) I was in a position of sort of receiving information from them around how things would go.'

In similar vein, the managers' experienced that selected support services on the plan did not work on their specific department, nor were aligned with specialized job responsibilities.

'They said: "Well, she can come back supernumerary." And I said, "What do you mean, supernumerary? I'm three positions down. So there's no way you can come and be somebody's shadow here. It doesn't work like that".'

In realizing a plan, the managers expect better insight in worker's expected progress and a better understanding of worker's abilities. Yet they do not receive this. On the contrary, the managers are left to feel dubious about how assessments and selected services come about and if the individual worker can meet the complexities of work. They feel they cannot contribute their practical insights to improve the plan before finalizing it. As a result of not including the workplace perspectives, the RTW plan does not materialize well in practice as will be addressed next.

\subsection{Return-to-work plan execution: Getting frustrated}

The managers saw themselves as having a key-role in the interface between the worker and the workplace:

'I think that the manager has a really key role in helping the employee see what's happening in the workplace. I think that's the extent of it. We have to help them and that we're interested in having them back to work but not having them back to work if they're not able. (...) if they're not able [to complete work], then it becomes a risk issue for themselves and a risk issue for care.'
From this perspective, the first concern regarding the RTW plan was that re-integrating workers did not always function as well as expected, according to the managers. They felt that the worker was sometimes not motivated for work ('work ethic') and/or did not meet what they perceived as agreed upon tasks, duties and hours. The managers mentioned they discussed unforeseen, subtle factors with the worker. However, they experienced it was sometimes hard to know how to approach this worker's situation (see also previous theme on what they could or could not say, or ask).

'When we first started this, it was like, "Don't try to take on too much." And that's the other problem is that the person feels like you're telling them, they'd better take on more, which makes them less productive. You know, so it's hard to know how to approach them.'

The managers experience difficulties when re-integration plans are not working out as expected. They find it sometimes difficult how to best address practical difficulties.

The second concern the managers pointed out was that difficulties in RTW could, in their view, create unwanted tension at the workplace (e.g. the worker reported sick again). They stated that (repeated) sickness absence and limited work ability puts more responsibility and pressure on co-workers. The managers perceived this could result in turn and over time in tension, resentment and mistreatment among other staff members:

'So sometimes there is that resentment. I know that goes on. Now whether that's verbal, or you just sort of hear it through the grape vine, "don't bring her in my area; she's really of no help to me" or "he can't help". So it's the chronic ones that I think are probably mistreated, maybe because they're misunderstood.'

The managers obtain better insight into practical difficulties in re-integration efforts, and experience tension on the floor if RTW plans do not work as expected.

The third concern the managers pointed out were unfilled expectations on monitoring by 'experts'. According to them, reviewing progress and, in turn, their expectation to address practical difficulties with 'experts' early on was not happening:

'I didn't know enough about Return To Work (...). I emailed the advisor, just with my questions and it took a long time to get any response. That was 
the most frustrating for me, that time kept passing and I wasn't getting any kind of response! (...) It would be nice to be able to go back to the Return To Work advisor and say, “This is what I'm noticing, is there any[thing we can do]?".'.

There are managers who argued that upon making contact with 'experts' to voice practical concerns they were countered with 'must' arguments to follow organizational routines and procedures on RTW versus reconsidering the appropriateness of plans:

'Return To Works are always set up Monday to Friday because that's when they say the most support is in the hospital, but it's also the busiest. (...) But [a] Return to Work is not allowed to work in the evening and they're not allowed to work on a weekend. So you're putting them in at the busiest time!'

Other managers mentioned that being countered with arguments to 'follow the rules', upon raising worker's difficulties to complete workload and the person functioning on the floor was not improving does nothing to solve re-integration problems, which they expected:

'I've tried talking to the unions [that the worker could not meet work demands] but I guess because it's in the Collective Agreement that's what we have to do, that's what we have to do.'

The managers experience that measures for evaluating practical problems and integrating the workplace perspective in RTW process are unclear to them. They find that careful handling by 'experts' of daily difficulties is not taking place. This is upsetting to the managers, especially in perceived (poor) combination with 'experts' counters to follow the rules. Workers oftentimes return to their own job or accommodated job before details on work (in-) capacities are worked out as we will see in the next section.

\subsection{Final return-to-work strategy: Getting overextended}

In the final phase, formal assessment on RTW or integration to own job or accommodated job is completed. Workers are no longer designated for RTW programming or 'extra' support services and are expected to complete duties and tasks in line with the job responsibilities.

The first concern the managers highlighted was that workers' capacity to meet the complexities of work remained unpredictable and unexpected limitations could still become clearer upon formalized re-integration. For example, there are managers who stated getting concerned when other staff (silently, discretely) pointed out that the re-integrated worker to his/her own job or accommodated job was making errors in patient care:

' $\mathrm{He}$ is needing to be directed much more than he did prior to going off on his illness. He is missing treatments and medications and, you know, those small mistakes that I don't believe he ever made prior to being off.'

The managers mentioned tenseness at the department rising (also see previous theme on tension) as re-integrated workers were on occasion assigned duties/tasks which other staff considered 'promotion opportunities':

'There are people who have worked within that department for over 20 years. All of a sudden someone comes in, kind of what they perceive as through the back door (...) and you're kind of feeling... frustrated.'

The managers thus experience that unexpected, subtle worker' incapacities around healthcare service delivery and inconsiderate job accommodations raises tension on the work floor.

The second concern the managers pointed out was the lack of follow-up care to deal with such unforeseen practical difficulties in relation to the re-integrated worker and the workplace:

'Once they go on their own nobody is following them up. I mean, I am and their co-workers are, but we don't have any way of returning that. Maybe they are not interested in how they do once they go back on their own; I don't know.'

In more detail, there are managers who highlighted that the human resources department (which they have to deal with and includes DMPs) and external agents did not recognize their calls, e-mails, consultations hence workplace arguments that workers were having unexpected, new incapacities in meeting (fluctuating, increasing) job demands. They argued that 'experts' encouraged a 'keep going' approach and in doing so failed to acknowledge they might set re-integration up to fail:

'They didn't understand the disabilities we were talking about (...) The people in terms of [name organization] were useless, absolutely non helpful.' 
The managers experience there is a lack of followup in care to ensure workers with incapacities meet job complexities. They find a lack of accountability of support services in terms of recognizing experienced difficulties, help problem solve and offer possible solutions. In the end, the managers find that the worker's limitations might not be acknowledged by the worker themselves (e.g. in light of financial worries the worker may have to report ill again, or worries to lose their job) and may neither be recognized, explored nor considered by (health, re-integration) professionals.

The managers respond in different ways to these practical bottlenecks. In some situations, managers left it up to the worker to report in sick again (see previous themes), whereas other managers attempted to work out details. The managers acknowledged getting a better understanding what was going on from worker's perspective was important and could require a shift in working relations (e.g. for the worker to start sharing personal/private difficulties, for the individual and team to cooperate - a give-and-take approach), which did not always occur. They pointed out to realize that sometimes the re-integrated worker really needed to see a physician for a better diagnosis and, in turn, better targeted treatment and support at work. For this realization to mature, the managers mentioned successful interactions with knowledge allies they had (e.g. College of Nurses, physicians). Building this bridge between external health professionals and the workplace, however, was a lot of effort:

'I had to do a lot of work around articulating what we were seeing and whether that made any sense for him and gave him stuff to take to his physician. (...) What worked well was finally to help both this employee and his physician realize that by continuing to put him in the workplace he was going to lose any prospective (...) which in my mind was completely unfair.'

The managers experience that improving work relations can, in turn, enhance articulation of re-integration difficulties. This, in turn again, can support decisionmaking in organizing individual re-integration relative to operational work processes. The managers find it unacceptable that failure to get a good diagnosis for accurate treatment and to coordinate work demands and support can potentially result in workers losing their job or professional license.

Nevertheless, the managers pointed out that worker's incapacity could sometimes permanently hamper work flow and ultimately organizational objectives. They sometimes simply could not solve nor stretch themselves any further, according to them. For this the managers pointed to the system/organization and their responsibility for better organizing RTW policy:

'My concern actually is, is how the system is put in place (...) I think there should be some more consideration about what we do and how they can help us operationally, make it work. I don't feel that. It's as simple as that.'

The managers experience that despite their willingness to meet the expectation to re-integrate workers with incapacities, the formal RTW policies and procedures do not comply with the work they have to do. They find that if they improve their understanding of health issues that affect the worker' capacity they can, in turn make efforts in adjusting the specific strategies the worker employs to meet work demands. But which cause worker health problems (e.g. being too altruistic or "can do" approach which can result in problems relating to what are called issues in psychosocial functioning) they cannot change. The managers then feel wronged and overextended having to sort-out RTW difficulties and issues (e.g. work stress, when work demands exceed the worker's ability to cope or control on their own).

\section{Discussion}

In a leading healthcare organization in BC, Canada, RTW policy was reformed in which (early) re-integration of workers with incapacities as well the management' participation and the inclusion of the workplace perspectives in RTW process was encouraged. The study examined how, in practice, policy execution of this bipartite agreed upon organizational RTW policy was experienced by the management. We conducted 10 interviews with clinical managers and direct supervisors who were each involved in several RTW trajectories of various re-integrating workers.

The management took steps to meet the organizational objective of re-integrating workers with incapacities. However, they experienced their organization and other involved institutions not keeping the bipartite agreement that encourages managers' participation and inclusion of the workplace perspectives in RTW process. Consequently, the management found it unacceptable that poorly implemented RTW policy can put the delivery of healthcare services at stake and can 
exclude workers with incapacities from participating in the workforce. Moreover, managers felt oftentimes blamed as the ones at fault. This study is one of few studies with a management perspective on RTW policy [6,37-39]. Though some studies on workers' perspectives on RTW policy suggest that management oftentimes does not want to support workers with incapacities in re-integration $[37,38]$, our study illuminates the management' trials to do just that.

RTW policy gives managers the responsibility to ensure the plan is attuned to the worker's limitations relative to the job responsibilities. Asking for manager's input is in line with the obligation to find a way to accommodate the worker and is supposed to ensure plans fit the practical experiences of managers. In practice, however, at the moments when decisions on a plan have to be made, managers do not have a clear picture of worker's limitations. The management thus has to offer adapted work places without knowing what to adapt. At the same moment, as RTW plans are formal decisions, the management is bound to the proposals they make on the plan. In addition, RTW policy demands that the management implements this RTW plan and supports this re-integration. It is managers' responsibility to notify the workplace and organize the selected strategies. Yet, due to uncertainties in the assessment of limitations during the design of the plan, the management finds often that unexpected worker's limitations occur during re-integration. Furthermore, managers encounter that re-integration trajectories are time and again unpredictable and non-linear. The management gets that unpredictability of illness process are not taken into account within the plans and they do not get help or facilitation to deal with the various limitations and differing dilemmas that happen. The mistaken assessments of re-integration result in costs and efforts shouldered by the management. RTW policy also gives the management responsibility for workers who completed RTW programming. The 'idea' is for workers to be recovered after four-six weeks of support services, albeit extensions can be requested. In practice, however, the managers find unexpected limitations and various dilemmas remain to be an issue for which, again, they are not facilitated. They can sometimes work these difficulties out but it stretches managers and in some cases they simply do not succeed in getting or keeping adaptations in place. Managers are forced to deal with costs and effort to figure out unresolved value disputes on implications of illness and guidance for re-integration.

When compared to the findings of an earlier study on workers' experiences with and perceptions on the same RTW policy [11] striking similarities were found. These authors demonstrated with empirical research how policies for involvement, in this Canadian setting of work re-integration, were not as effective as intended, and excluding consequences of these policies. They concluded that, in practice, the procedures did not result in better RTW practice due to timing of involvement, recognition of practical insights and support services or lack of it.

\subsection{The discretionary space}

The social constructivist view on the policy process assumes a natural gap to exist between policy and policy execution, which allows for discretionary space. The findings of Maiwald et al. [11] among workers and the current study among managers demonstrate that the misconception on the extent to which RTW can be planned in advance is the major bottleneck. In bipartite agreed upon RTW policy the importance of both worker' and manager' involvement in re-integration is acknowledged, and both stakeholders' perspectives have to be included on the plan. The first assumption in this RTW policy is that at the moment the plans have to be defined, which is before RTW itself starts, both stakeholders can provide information relevant for this re-integration. Although medical advisors demand workers' input, the advisors cannot predict what the limitations and possibilities of the worker are and how they will develop, resulting in plans based on inadequately defined limitations. While managers are asked for input on plans that appear inadequate, they cannot suggest appropriate adjustments or make adjustments on the plan. A second assumption in this RTW policy is that 'sitting around the table with all the stakeholders' is the best process to guarantee that deep-rooted differing interests of managers and workers are brought forward on the plan and are reckoned with during reintegration. However, these (re-) negotiations are far more difficult than assumed. Workers are uncomfortable in meetings and managers find that, despite seeing themselves as having a key-role, they cannot get practical difficulties addressed. Both workers and managers find that internal health and re-integration professionals and external compensation agents do not help to problem solve nor facilitate.

This study demonstrates that inflexibility and inability of arrangements for RTW are counterproductive for managers to meet re-integration objectives, in combination with other organizational demands. This same inflexibility and inability of arrangements for RTW af- 
fected the workers' chances to succeed in the work abilities they theoretically had and their real work participation [11].

This study thus shows clear tension between bipartite-agreed upon RTW policy and policy execution, and the discretionary space becoming an organizational sub-level battleground. Insight in how the discretionary space is interpreted is relevant because it demonstrates the nucleus of this tension in this organizational context, and further draws attention to unintended consequences of these bipartite policies in this setting.

The finding of Maiwald et al. [11] and the current study demonstrates the same policy paradox [24]. The policy intention is more responsibility to be given to the management and workers and better support by health and re-integration professionals. However, both the managers and workers experience the inability to complete responsibilities and run into practices of (social) exclusion in consultation processes. The findings of both studies therefore support the tentative conclusion that bipartite involvement in RTW policy process does not guarantee that policies and procedures are better adjusted to processes in practice. More research is needed regarding what input these bipartite representatives have and how they interpret and translate managers and workers interests into policy to meet the complexity of work re-integration.

\subsection{Limitations}

The number of interviewees involved in this study may be seen as a limitation. Bias in case selection could not be avoided as the respondents were selfselected. Our methods ensured the selection of a diverse range of managers and data collection was performed in two stages, yet, saturation might not have been reached on the practice of work re-integration in the entire BC healthcare sector in Canada. Using both a theoretical framework to design this study and analyse the data supports trustworthiness of findings and gained insight into various mechanisms which hamper implementation of reformed RTW policy.

\subsection{Implications for practice and further research}

Several implications of the study for practice and recommendations for further research can be made. The results of this study demonstrate that illness processes are capricious and RTW trajectories are dynamic and therefore re-integration planning requires continued adaptations. To address this, the manage- ment indeed seemed to need a more central role during re-integration, which is in line with conclusions from other research [22,23]. Nonetheless, on-going modification of plans based on practical insights must be guaranteed. For example, in the Netherlands there is room for adjustments and RTW plans should be allowed flexibility in which try-out opportunities and room (timing for involvement and choosing another intervention) must be based on gained insights in the various stakeholders' perspectives [26,40].

Another vital point for practice improvement is that health and re-integration professionals are supposed to support the new role of the management during reintegration [41]. Nonetheless, the management does not experience this service is happening in practice. Research shows challenges and opportunities regarding the supporting role of health care and re-integration professionals $[6,22,42,43]$, also from the perspective of costs being made by management [39]. Soklaridis and colleagues demonstrated in a Canadian setting that management felt the relevance of making medical costs but also experienced them as a financial burden on the management [39].

While the findings of this study on RTW policy are specific to the local context, there are lessons to be learned for other settings. First, RTW policy implementation is linked to the social security legislation regarding RTW. The current positive attitudes of managers towards RTW might be rooted in the extensive RTW legislation in Canada. Lack of management involvement is found in settings with dearth of legislation, such as in Belgium [44]. Second, the implementation of a new policy in the health care sector needs to be understood in the light of its structural characteristics [45]. The present positive views and behaviours of managers towards seeking alternative ideas on guidance in re-integration might be because they embrace changing professional and work/organizational structures in this sector.

\section{Conclusions}

Management representatives' involvement in RTW policy process does not reduce bottlenecks in reintegration programming and thus does not secure implementation of agreed upon policy. Our current study shows that on the one hand, more flexibility in practice is needed to allow for active participation of managers. On the other hand, strictness is needed regarding taking responsibility by stakeholders, particularly the 
health care and re-integration professionals. The findings did not contradict that found in a study among workers who were re-integrating into work in the same setting, but rather appeared to parallel these. Bipartite representation in the RTW policy process and how representatives exert their authority to formulate rules and policies needs further study.

\section{Acknowledgements}

We are grateful to the participants of this study. The authors kindly acknowledge Dr. Jaime Guzman, M.D., MSc, FRCPC and Renée-Louise Franche, PhD, both former OHSAH, BC, who supervised data-collection in Canada. This work was financially supported by former OHSAH, BC, Canada through a Research Fellowship for Karin Maiwald. She further acknowledges the Work Disability Prevention Canadian Institute for Health Research (CIHR) Strategic Training program, University of Sherbrooke, Montreal/University of Toronto, Dalla Lana School of Public Health, Toronto, Canada.

\section{References}

[1] Statistics Canada (2010) Topics of interest on labour and income. Work absences at: http://www.statcan.gc.ca/pub/75001-x/topics-sujets/topics-sujets-eng.htm, Last accessed on December 3, 2012.

[2] Kalisch DW, Aman T and Buchele LA (1998) Social and Health Policies in OECD Countries: A Survey of Current Programmes and Recent Developments. OECD Labour Market and Social Policy Occasional Papers 33. OECD Publishing at: http://dx.doi.org/10.1787/720018345154, Last accessed on December 3, 2012.

[3] OECD (Organization for Economic Co-operation and Development). (2003). Transforming disability into ability. Policies to promote work and income security for the disabled. Paris: OECD.

[4] WHO (World Health Organization). (2006) The World Health Report 2006 - working together for health at: http://www. who.int/whr/2006/en/index.html, Last accessed on December 3, 2012.

[5] ILO (International Labour Organization) (2001) Code of Practice on managing disability in the workforce at: http:// www.ilo.org/public/english/standards/relm/gb/docs/gb282/ pdf/tmemdw-2.pdf, Last accessed on December 3, 2012.

[6] Westmorland MG and Buys N (2004) A comparison of disability management practices in Australian and Canadian workplaces. WORK 23, 31-41.

[7] MacEachen E, Kosny A and Ferrier S (2007a) Unexpected barriers in return to work: Lessons learned from Ontario injured worker peer support group. WORK 29(2), 155-64.

[8] MacEachen E, Ferrier S, Kosny A and Chambers L (2007b) A deliberation on "hurt versus harm" logic in early return to work policy. Policy and Practice in Health and Safety 5(2), 41-62.
[9] MacEachen E, Kosny A, Ferrier S and Chambers L (2010) The 'toxic dose' of system problems: Why some injured workers don't return to work as expected. J Occup Rehabil 20(2), 349-66.

[10] Maiwald K, De Rijk A, Guzman J, Schonstein E and Yassi A (2011) Evaluation of a workplace disability prevention intervention in Canada: examining differing perceptions of stakeholders. J Occup Rehabil 21(2), 179-89.

[11] Maiwald K, Meershoek A, De Rijk AE and Nijhuis FJN (2013). How policy on employee-involvement in work reintegration can yield its opposite: employee experiences in a Canadian setting. Disabil Rehabil 35(7), 527-537.

[12] Tjulin A, MacEachen E and Ekberg K (2011) Exploring the meaning of early contact in return-to-work from workplace actors' perspective. Disabil Rehabil 33(2), 237-145.

[13] WSBC (WorkSafeBC). Workers Compensation Act at: http:// www.worksafebc.com/about_us/governance/default.asp, Last accessed on December 3, 2012.

[14] WSIB (Workplace Safety and Insurance Board). (2010) Annual Report 2010 at: http://www.wsibontario.ca/PDF/Online AR_E_2010.pdf, Last accessed on December 3, 2012.

[15] Franche RL, Baril R, Shaw WS, Nicholas M and Loisel P (2005) Workplace-based return-to-work Interventions: optimizing the role of stakeholders in implementing and research. J Occup Rehabil 15(4), 525-42.

[16] Guzman J, Yassi A, Baril R and Loisel P (2008) Decreasing occupational injury and disability: The convergence of systems theory, knowledge transfer and action research. WORK: 30 (3), 229-39.

[17] Van Oostrom S, Anema JR, Terluin B, Venema A, De Vet HC and Van Mechelen, W (2007) Development of a workplace intervention for sick-listed employees with stress-related mental disorders: Intervention Mapping as a useful tool. BMC Health Services Research (7), 127.

[18] Ouellette V, Badii M, Lockhart K and Yassi A (2007) Worker satisfaction with a workplace injury prevention and return-towork program in a large Canadian hospital: The importance of an integrated approach. WORK 28(2), 175-81.

[19] Van Petersen A, Vonk M and Bouwmeester M (2004) Onbekend maakt onbemind: Attitude onderzoek naar de positie van arbeidsgehandicapten op de arbeidsmarkt. [Unknown makes unloved: Attitude research into the position of work disabled people into the jobmarket]. Research voor beleid [Research for policy], Leiden at: http://www.ohcbv.nl/hulppagina/docu menten/Onbekend\%20maakt\%20onbemind.pdf, Last accessed December 03, 2012.

[20] CWP (Commissie het Werkend Perspective) (2007). Bouwen op vertrouwen [Committee the Working Perspective. Build on trust]. CWP, Den Haag.

[21] Kaye SH, Jans LH and Jones EC (2011) Why Don't Employers Hire and Retain Workers. J Occup Rehabil 21, 526-36.

[22] Nieuwenhuijsen K, Verbeek JHAM, De Boer AGEM, Blonk RWB, Van Dijk FJH (2004) Supervisory behavior as a predictor of return to work in employee absent from work due mental health problems. J Occup Environ Med 61(10), 817-23.

[23] Munir F, Yarker J, Hicks B and Donaldson-Feilder E (2012) Returning Employees Back to Work: Developing a Measure for Supervisors to Support Return to Work (SSRW). J Occup Rehab 22, 196-208.

[24] Stone DA (2002) Policy paradox: the art of political decision making, Norton and Company, New York-London.

[25] Lipsky M (1980) Street-level Bureaucracy: Dilemmas of the Individual in Public Services, Russell Sage Foundation, New York. 
[26] Meershoek A, Krumeich A and Vos R (2007) Judging without criteria? Sickness certification in Dutch disability schemes. Sociol Health Illness 29(4), 497-514.

[27] Meershoek A and Krumeich A (2009) Multiculturalism and the Construction of Ethic Identities in Labour and Health Practices: Avoiding the Culturalistic Fallacy in Applied Research. Health Care Analysis 17, 173-97.

[28] Van der Veen RJ (1990) De sociale grenzen van beleid: een onderzoek naar de uitvoering en effecten van sociaal beleid [The social boundaries of policy: a study into the implementation and effects of social policy], Stenfert Kroese, Leiden.

[29] Van der Veen RJ (1992) De transformatie van beleid [The transformation of policy] in Het bereik van de wet [The reach of the law], eds. Witteveen WJ, Stout HD, Trappenburg MJ, Tjeenk-Willink, Zwolle, 63-80.

[30] Boeije H (2010) Analysis in Qualitative Research, Sage, Los Angeles.

[31] Hammersley M and Atkinson P (2007) Ethnography: principles in practice, Routledge, London.

[32] Tedlock B (2005) The observation of participation and the emergence of public Ethnography in Handbook of qualitative research, eds. Denzin NK and Lincoln, Sage, Thousand Oaks, 467-81.

[33] Stake R (2005) Qualitative Case Studies in Handbook of Qualitative Research, eds. Denzin NK and Lincoln YS, Sage Publications, Thousand Oaks, 443-66.

[34] Denzin NK and Lincoln YS (2005) Handbook of qualitative research, Sage, Thousand Oaks.

[35] Polit, DF and Beck, CT (2004) Nursing research: principles and methods, Lippincott Williams and Wilkins, Philadelphia PA.

[36] Corbin J and Strauss A (2008) Basics of qualitative research: techniques and procedures for developing grounded theory, Sage, Thousand Oaks.

[37] Feuerstein M, Luff GM, Harrington CB and Olsen CH (2007)
Patterns of workplace disputes in cancer survivors: A population study of ADA claims. J Cancer Survivor 1, 85-192.

[38] MacEachen E, et al. (2012), The 'Ability' Paradigm in Vocational Rehabilitation: Challenges in an Ontario Injured Worker Retraining Program. J Occup Rehabil 22, 105-17.

[39] Soklaridis S, Cassidy JD, van der Velde G, Tompa E and Hogg-Johnson S (2012) The economic cost of return to work: An employer's perspective. WORK 43, 255-262.

[40] Anema JR, Schellart AJ, Cassidy JD, Loisel P, Veerman TJ and Van der Beek AJ (2009) Can cross country differences in return-to-work after chronic occupational back pain be explained? An exploratory analysis on disability policies in a six country cohort study. J Occup Rehabil 9(4), 419-26.

[41] Pransky G, Shaw WS, Loisel P, Hong QN and Désorcy B (2010) Development and Validation of Competencies for Return to Work Coordinators. J Occup Rehabil 20(1), 41-48.

[42] Hoefsmit N, Houkes I and Nijhuis FJN (2012) Intervention Characteristics that Facilitate Return to Work after Sickness Absence: A Systematic Literature Review. J Occup Rehabil 22, 462-477.

[43] Eikenaar T, Van Groenestijn M-H, De Rijk A and Meershoek A (2012). Goed bespiegeld, beter begeleid! De rol van grondhoudingen in re-integratiebegeleiding en de vertaling ervan in het reflectie-instrument 'MIRROR'. [Good reflection, better support! Frames of references in reintegration support and translation into the reflection instrument 'MIRROR'], Maastricht University Press, Océ Business Services, Maastricht.

[44] Tiedtke C, Donceel P, Knops L, Désiron H, Dierckx De Casterlé B and De Rijk A (2012) Supporting Return-to-Work in the Face of Legislation: Stakeholders' Experiences with Return-to-Work After Breast Cancer in Belgium. J Occup Rehabil 22 (2), 241-251.

[45] Hirschkorn KA and Bourgealt, IL (2008) Structural constraints and opportunities for CAM use and referral by physicians, nurses and midwifes. Health 12(2), 193-213. 